\title{
Flexible diamond-like carbon film prepared by hydrothermal electrochemical method
}

\author{
YING TAO $^{1, *}$, DANQIN YI ${ }^{1}$, BAOJUN ZHU $^{2}$ AND WENPENG CAO ${ }^{1}$ \\ ${ }^{1}$ School of Materials Science and Engineering, Central South University, Changsha 410083, China \\ ${ }^{2}$ School of Materials Science and Engineering, Hunan University, Changsha 410082, China
}

\begin{abstract}
Diamond-like carbon (DLC) thin films were prepared by hydrothermal electrochemical method in one-step process. The structural characterization of these films was carried out by scanning electron microscopy (SEM), Raman spectroscopy, and infrared reflectance spectroscopy (IR). It was found that there was an increased $\mathrm{sp} 2$ carbon content but decreased $\mathrm{sp} 3$ carbon and hydrogen contents with an increase in current density. The flexibility and internal stresses of the DLC films were affected by hydrogen, sp3 amorphous carbon and ordered crystalline sp2 carbon contents. The highly flexible DLC films with high sp3 carbon and hydrogen contents were prepared at a current density of $0.001 \mathrm{~mA} / \mathrm{cm}^{2}$.
\end{abstract}

Keywords: diamond-like carbon; thin film; flexible; hydrothermal electrochemical method

\section{Introduction}

DLC films remain a subject of interest due to their attractive optical, electrical, chemical, mechanical properties and biocompatibility [1-5]. Common methods for depositing DLC films include chemical vapor deposition (CVD), physical vapor deposition (PVD), ion beam assisted deposition (IBAD) and electrochemical deposition [3-7]. However, poor adhesion of common DLC films on a variety of substrates results from the high residual stress, which limits their applications [8]. The flexible DLC films are representative films with low residual stress, which do not peel off easily [9].

In this paper, an inexpensive and environmental friendly hydrothermal electrochemical process was developed for preparing flexible DLC films [10]. The residual stress in thin films has two sources: thermal and intrinsic [11]. Thermal stress in the DLC films is quite low, because of relatively low reaction temperature (below $200{ }^{\circ} \mathrm{C}$ ). The magnitude of internal stresses in the DLC films depends upon their microstructure, including component phases and impurities [12]. In this work, an attempt was made to study the effect

*E-mail: yuzi256@126.com of microstructure on deformation behavior (caused by internal stress) of DLC films prepared by hydrothermal electrochemical method.

\section{Experimental}

Tantalum substrates of 99.9 wt.\% purity with $10 \mathrm{~mm}^{3} \times 10 \mathrm{~mm}^{3} \times 0.1 \mathrm{~mm}^{3}$ dimensions were mechanically polished and degreased with acetone using an ultrasonic cleaner. Reaction solutions were prepared by dissolving $0.19 \mathrm{~g}(0.001 \mathrm{~mol})$ of glucose in $100 \mathrm{~mL}$ of distilled water.

A detailed description of the deposition facility and the growth method has been done elsewhere [13]. After each experiment, the DLC films were deposited on tantalum substrates at a temperature of $200{ }^{\circ} \mathrm{C}, \mathrm{DC}$ current density ranging from $0.001 \mathrm{~mA} / \mathrm{cm}^{2}$ to $0.05 \mathrm{~mA} / \mathrm{cm}^{2}$, and duration of up to $20 \mathrm{~h}$. The samples a, b, c and d were prepared at current densities of $0.001 \mathrm{~mA} / \mathrm{cm}^{2}, 0.003 \mathrm{~mA} / \mathrm{cm}^{2}$, $0.01 \mathrm{~mA} / \mathrm{cm}^{2}$, and $0.05 \mathrm{~mA} / \mathrm{cm}^{2}$, respectively. The samples were washed with water, ultrasonically in ethanol, and air-dried prior to characterization.

The surface morphologies of the films were investigated by scanning electron microscopy (SEM, JSM-6301F). The structural properties were 


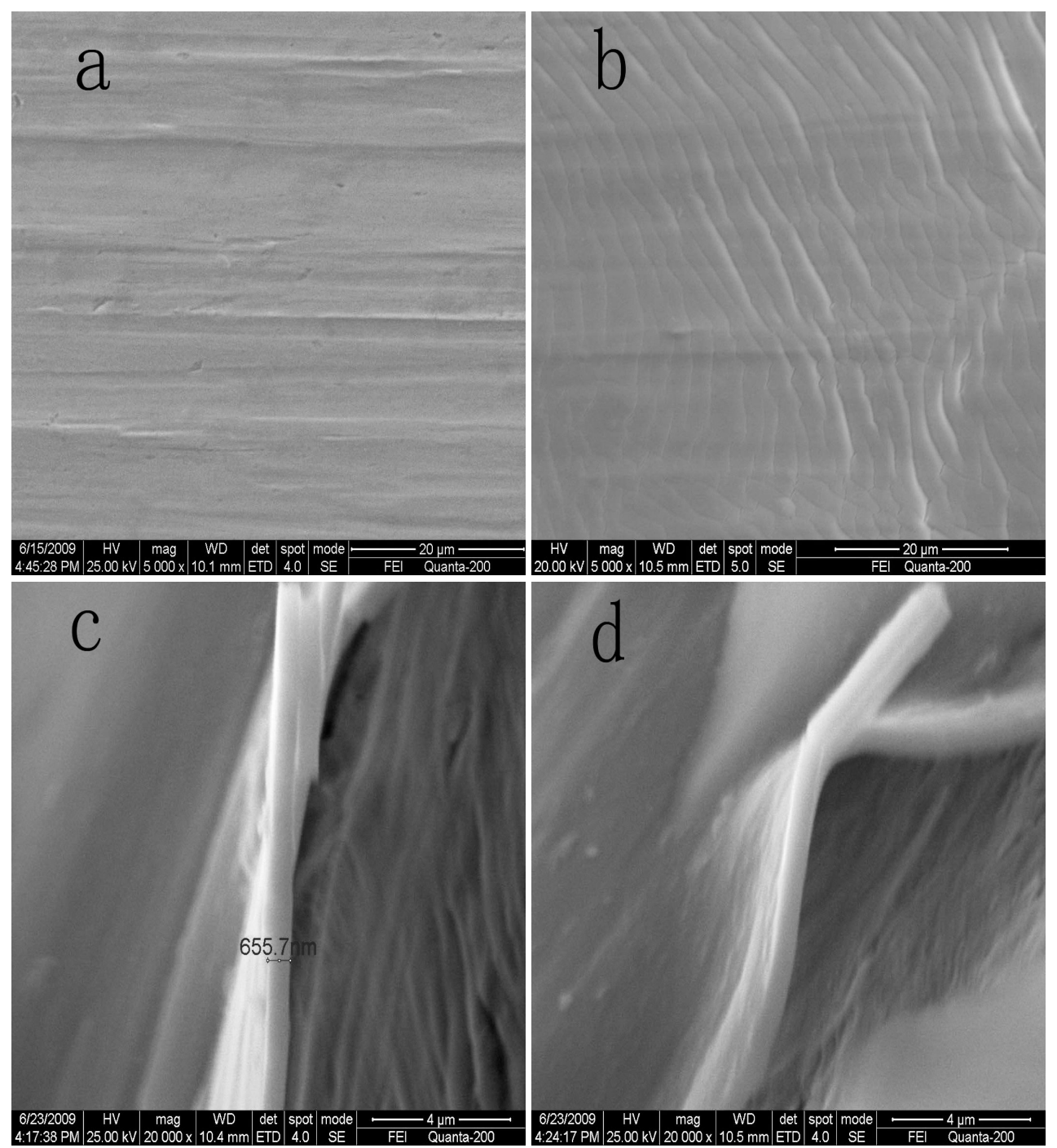

Fig. 1. SEM micrographs of sample a (a) surface before deformation, (b) surface after bending, (c, d) cross section after twisting.

characterized by Raman spectroscopy (Labram HR 800, Jobin-Yvon), and infrared reflectance spectroscopy (IR, Nexus 670).

\section{Results and discussion}

\subsection{SEM characterization}

Sample a shows unique mechanical properties. After 180 degree bend, the smooth flat surface became ragged with successive strips as shown in Fig. 1a and Fig. 1b. The successive strips (without cracks) could be caused by plastic flow of DLC films during bending deformations. After 45 degree twist, the film with the thickness of $655 \mathrm{~nm}$ peeled off the substrate but did not break into fine fragments as shown in Fig. 1c and Fig. 1d. It indicates that the films are characterized by high plastic flow and low internal stress.

Fig. 2 shows the micrographs of sample $b$ before and after 180 degree bend. The smooth surface became ragged and created discontinuous strips. The width and brightness of the strips are not uniform. The visible bright zones correspond to wide strips while the dark zones correspond to narrow strips. There are many cracks among the bright 
wide strips. They may be attributed to plastic flow firstly generated during bending deformation, then fracturing and warping in some places. It shows that the films have rather poor flexibility.

Sample $\mathrm{c}$ has been broken into strips and peeled off after 180 degree bend, as shown in Fig. 3. There is no trace of plastic flow in the strips. It can be attributed to high internal stress which makes the films peel off from the substrate surface [11].

As shown in Fig. 4, there is a great number of reticulate craze cracks on the surface of sample $d$ without any deformation. They may result from the presence of extremely high internal stresses which could cause such crazing and cracking. The analysis of SEM images shows that the brittleness and internal stress of the samples have increased with increasing current density.

\subsection{Raman spectroscopy analysis}

Fig. 5 shows the Raman spectra of the deposited DLC films. The observed $G$ and $D$ peaks in the four kinds of the films reveal the existence of both sp2-type and sp3-type carbon bonding in the DLC films [14]. By fitting procedures, the intensity ratio of $\mathrm{D}$ band to $\mathrm{G}$ band $\left(\mathrm{I}_{\mathrm{D}} / \mathrm{I}_{\mathrm{G}}\right)$ for samples $\mathrm{a}, \mathrm{b}$, $\mathrm{c}$, and $\mathrm{d}$ has been found to be about $0.66,1.38$, 1.96 and 3.2, respectively. The $\mathrm{G}$ band peaks of the films are located at $1554 \mathrm{~cm}^{-1}, 1560 \mathrm{~cm}^{-1}$, $1565 \mathrm{~cm}^{-1}$ and $1569 \mathrm{~cm}^{-1}$, with a full-width at half-maximum (FWHM) values of $171 \mathrm{~cm}^{-1}$, $113 \mathrm{~cm}^{-1} 112 \mathrm{~cm}^{-1}$ and $102 \mathrm{~cm}^{-1}$ for the samples a, b, c, and d, respectively. The increase in the ratio of $I_{D} / I_{G}$, along with $G$ peak shifting to higher wave numbers and the narrowing of $G$ peak indicate an increase in the content of crystalline sp2-bonded graphite carbon in the samples [15]. It can be concluded that as the current density increases, the color of the films becomes brighter and the quantity of ordered sp2-bonded clusters (graphite) increases. In sample $d$, obtained at the highest current density, the content of multiple ordered sp2-bonded clusters (graphite) is the highest. The peak at about $1120 \mathrm{~cm}^{-1}$ to $1160 \mathrm{~cm}^{-1}$ is not observed in sample d. However, such peak is observed in other samples. This can be attributed to relatively high content of sp3-bonded amorphous matrix in the deposited DLC films [16]. The presence of high content sp3 bonding in samples $a$ and $b$ is further confirmed by the very noisy Raman spectra in Fig. 5a and Fig. 5b, because the amorphous sp3 carbon could absorb the incident laser energy and Raman scattered energy [16]. In addition, laser energy could lead to transformation of amorphous carbon into graphite during Raman scanning. So, the relative intensity of the Raman spectra increased with increasing scan numbers.

\subsection{Infrared reflectance spectroscopy analysis}

Fig. 6 shows the IR reflection spectra of the deposited films. In Fig. 6a and Fig. 6b, the band at $2983 \mathrm{~cm}^{-1}$ represents sp3 $\mathrm{CH}_{3}$ anti-symmetric vibration and the other two vibrations at $2928 \mathrm{~cm}^{-1}$ and $2873 \mathrm{~cm}^{-1}$ could be assigned to sp3 $\mathrm{CH}_{2}$ asymmetric and symmetric vibrations [17, 18]. This indicates that the bonding in samples a and $\mathrm{b}$ is predominantly of $\mathrm{sp} 3$ type. The presence of sp3 bonding $(\mathrm{C}-\mathrm{H})$ in the film was further confirmed by the peaks at 1438 and $1368 \mathrm{~cm}^{-1}$ which are the modes associated with the bending of the $\mathrm{C}-\mathrm{H}$ bond [17]. Also, a strong $\mathrm{C}=\mathrm{C}$ stretching peak appears in the $1600 \mathrm{~cm}^{-1}$ region, which indicates the presence of a large number of $\mathrm{sp} 2 \mathrm{C}=\mathrm{C}$ groups [19]. This suggests that most of the carbon atoms in samples a and b are sp2 $\mathrm{C}=\mathrm{C}$ and sp3-hybridized carbon atoms. A weak $\mathrm{C}=\mathrm{O}$ bond $\left(1710 \mathrm{~cm}^{-1}\right)$ [20] and $\mathrm{C}-\mathrm{O}-\mathrm{C}$ bond $\left(1097 \mathrm{~cm}^{-1}\right)$ [21] can be identified clearly in samples $a$ and $b$. It proves the presence of a small amount of intermediate products (such as furfural and 5-hydroxymethyl-furfural-1-aldehyde (HMF)) in samples $\mathrm{a}$ and $\mathrm{b}$ [22]. The bands in the range of $1000 \mathrm{~cm}^{-1}$ to $1300 \mathrm{~cm}^{-1}$ (C-OH stretching and $\mathrm{OH}$ bending vibrations), together with the wide adsorption band at $3000 \mathrm{~cm}^{-1}$ to $3500 \mathrm{~cm}^{-1}$, imply the existence of a large number of residual hydroxyl groups [23]. In Fig. 6c and Fig. 6d, the very weak infrared bands at $1097 \mathrm{~cm}^{-1}$ and $1710 \mathrm{~cm}^{-1}$ in sample $\mathrm{c}$ and $\mathrm{d}$ can be assigned to the trace amounts of intermediate products. A peak corresponding to $\mathrm{sp} 3$ type carbon reported at $2900 \mathrm{~cm}^{-1}$ 


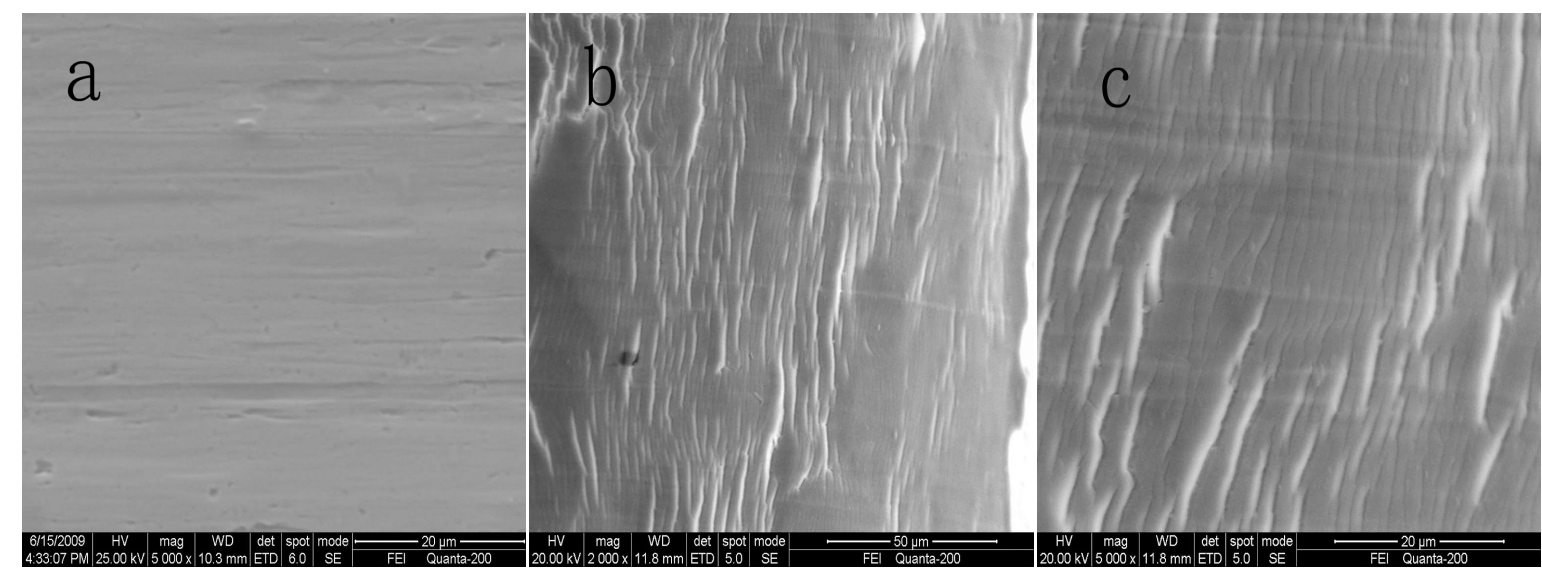

Fig. 2. SEM micrographs of the surface of sample b (a) before deformation (b, c) after bending.

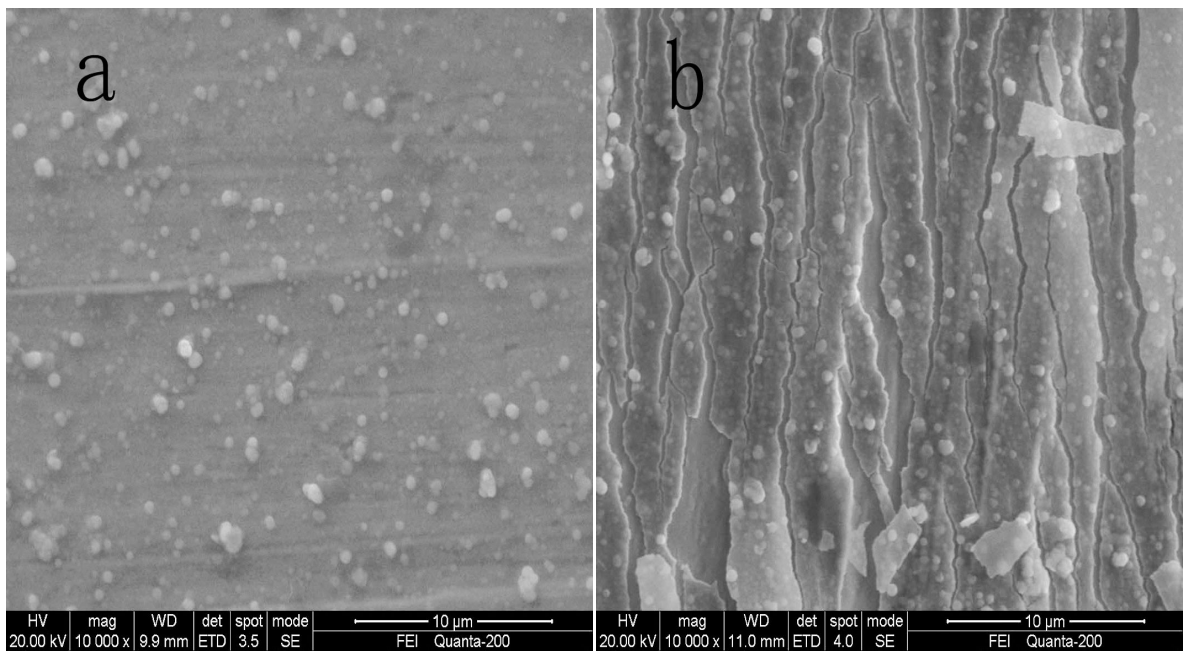

Fig. 3. SEM micrographs of the surface of sample c (a) before deformation, (b) after bending.

has not been identified in Fig. 6c and Fig. 6d, probably due to few amount of sp3 $\mathrm{C}$. This is also supported by relatively weak sp3 $\mathrm{C}-\mathrm{H}$ bending modes of carbon at $1447 \mathrm{~cm}^{-1}$ and $1368 \mathrm{~cm}^{-1}$. A strong peak observed at $1600 \mathrm{~cm}^{-1}$ can be ascribed to the presence of vast number of $\mathrm{C}=\mathrm{C}$ bonds in samples $\mathrm{c}$ and $\mathrm{d}$. It can be noted that samples $\mathrm{c}$ and $\mathrm{d}$ are composed of the vast majority of $\mathrm{sp} 2$ carbon bonds and a few sp3 carbon bonds. The IR reflectance results are consistent with those from Raman spectroscopy described earlier.

According to the analysis, there is an increased $\mathrm{sp} 2$ carbon amount but decreased sp3 carbon and hydrogen content at increased current density. The brittleness and internal stress could be increased by increasing the amount of ordered crystalline $\mathrm{sp} 2$ carbon. The films with high sp3 amorphous carbon and hydrogen content show better flexibility and lower internal stress. The results are not consistent with the typical view that DLC films with high sp3 content generally have also high internal stress. It is probably due to the formation of amorphous DLC films. To improve the properties of amorphous DLC films it would be advantageous to prepare films with higher content of sp3 atoms than that of sp2 and with low internal stress [24, 25]. Hydrogen for example reduces the internal stress of the DLC making it less susceptible to peeling [26]. Thus, the amorphous DLC films with high sp3 carbon and hydrogen contents are characterized by high flexibility and low internal stress. 


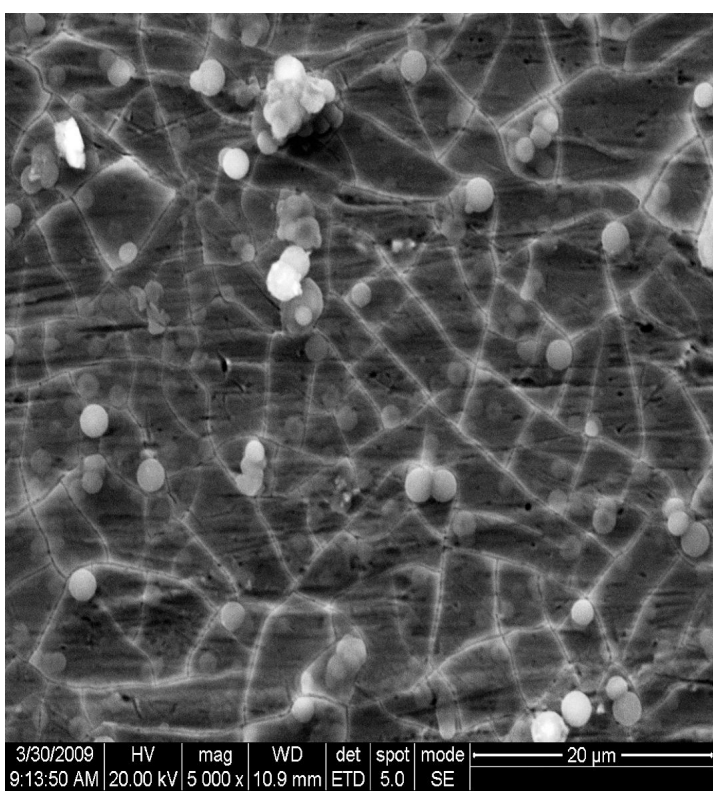

Fig. 4. SEM micrograph of the surface of sample d.

\subsection{Formation mechanism}

According to the earlier work [22], hydroxymethylfurfural (HMF) and furfural are important components in hydrothermal process. Fig. 7 shows the structural formula of HMF and furfural.

The opening of the furan ring is a normal occurrence. It is attributed to the relatively low aromaticity of the furan ring and low bond energy of carbon-oxygen-carbon bridge bond $(\mathrm{C}-\mathrm{O}-\mathrm{C})$. The bond energy of a C-O-C bond is about $280 \mathrm{~kJ} / \mathrm{mol}$. The oxygen atom in the furan ring has unpaired electrons, making it a nucleophilic compound. The suggested mechanism for ring hydrolysis (protonation) is shown in the scheme (Fig. 8) [27].

There are carbon-carbon double bond $(\mathrm{C}=\mathrm{C})$, carbon-carbon single bond $(\mathrm{C}-\mathrm{C})$, carbonhydrogen bond $(\mathrm{C}-\mathrm{H})$, carbon-oxygen double bond $(\mathrm{C}=\mathrm{O})$, and carbon-oxygen bond $(\mathrm{C}-\mathrm{OH})$. The bond energies for these bonds are $611 \mathrm{~kJ} / \mathrm{mol}, 278 \mathrm{~kJ} / \mathrm{mol}$ to $418 \mathrm{~kJ} / \mathrm{mol}$, $337 \mathrm{~kJ} / \mathrm{mol}$ to $431 \mathrm{~kJ} / \mathrm{mol}, 749 \mathrm{~kJ} / \mathrm{mol}$, and $456 \mathrm{~kJ} / \mathrm{mol}$, respectively [28]. In a given pair of atoms, a higher bond order results in a higher bond energy. So, we could draw the conclusion that the order of bond breaking is $\mathrm{C}-\mathrm{C}, \mathrm{C}-\mathrm{H}, \mathrm{C}-\mathrm{OH}$,
$\mathrm{C}=\mathrm{C}$, and $\mathrm{C}=\mathrm{O}$. Bond breaking is obviously an endothermic process. Applying a combination of an intense direct current (DC) electric field and moderately elevated temperature, the $\mathrm{C}-\mathrm{C}$ bonds between carbon 1 and 2, 3 and 4, and 5 and 6 break first followed by $\mathrm{HC}=\mathrm{O}, \mathrm{H}_{2} \mathrm{C}-\mathrm{OH}$; finally $\mathrm{HO}-\mathrm{C}=\mathrm{CH}$ carbon ions are formed [29].

Supersaturation is a driving force for all solution crystallization processes. The supersaturation in the process is a difference between the actual concentration and the solubility concentration of carbon ions at a given temperature [30]. The formation of carbon ions is attributed to hydrothermal and electrolytic decomposition of glucose. At the same temperature, a higher current density results in a higher concentration of carbon ions, which may exceed their saturation. In these conditions, some of carbon ions contact each other and homogeneous nucleation takes place in the solution, while some of carbon ions move to the electrode and form highly supersaturated solution and then heterogeneous carbon films on the electrode surface. At the same time, some homogenous crystal nuclei formed in the solution move to the electrode in the electric field and grow to spherical particles on the surface of carbon film as shown in Fig. 3 and Fig. 4. At low current density, the concentration of carbon ions might be lower than the saturation because of low electrolyte decomposition rate. Thus, the carbon ions transferred to the electrode surface form locally a relatively low supersaturated solution around the electrode because of low transmission speed of carbon ions (low current density). At a relatively low supersaturation, only the heterogeneous nucleation and growth of carbon take place on the electrode (substrate). So, at $0.001 \mathrm{~mA} / \mathrm{cm}^{2}$ and $0.003 \mathrm{~mA} / \mathrm{cm}^{2}$, no spherical particles are observed in Fig. 1 and Fig. 2.

Among $\mathrm{HC}=\mathrm{O}, \mathrm{H}_{2} \mathrm{C}-\mathrm{OH}$, and $\mathrm{HO}-\mathrm{C}=\mathrm{CH}$ carbon ions, the two previous could form sp3 carbon, the later carbon ions could form $\mathrm{sp} 2$ carbon. The high current density resulted in higher transfer ratio to the substrate, as well as more carbon ions transferred to the substrate and more $\mathrm{sp} 2$ and $\mathrm{sp} 3$ carbon formed. At the low current density, the supersaturation of carbon ions was low and forming 

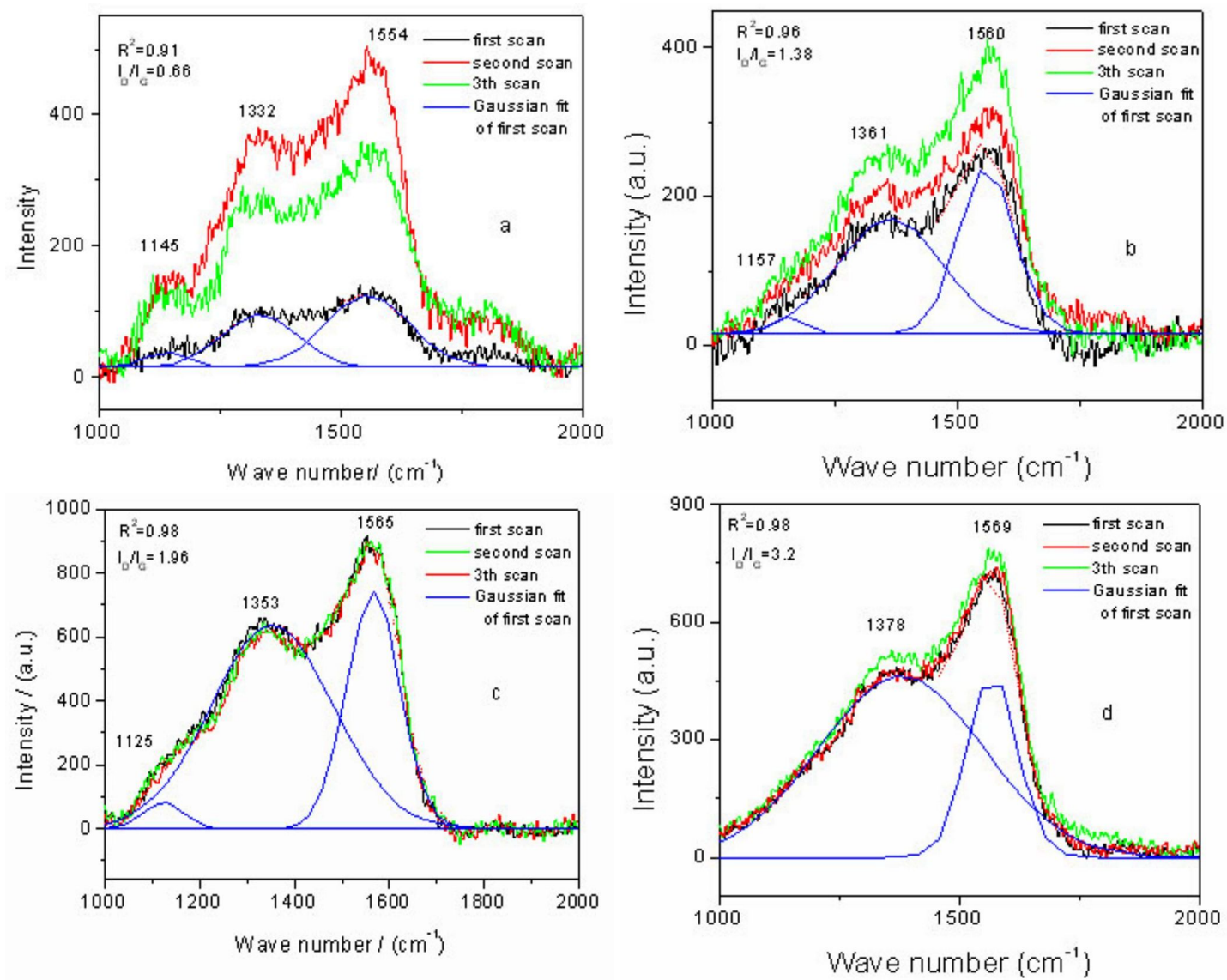

Fig. 5. Raman spectra of (a) sample a, (b) sample b, (c) sample c, and (d) sample d.

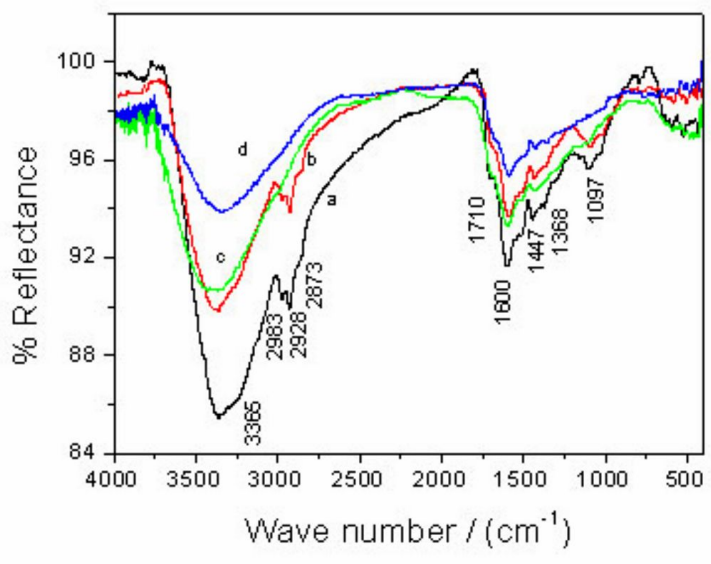

Fig. 6. Infrared spectra of (a) sample a, (b) sample b, (c) sample c, and (d) sample d.

sp2 carbon probably needed high energy. So, DLC films with high sp3 carbon and hydrogen contents were prepared at low current density.

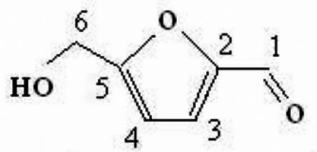

a

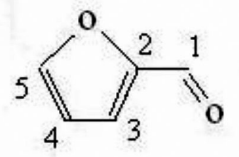

b
Fig. 7. Molecular structure of HMF (a) and furfural (b).

\section{Conclusions}

DLC thin films were prepared in this study by hydrothermal electrochemical technique using glucose as carbon source. An increase in current density caused an increase in ordered crystalline sp2 carbon content and a decrease in sp3 carbon and hydrogen contents, which led to the increase of brittleness and internal stress of DLC films. The flexible DLC films with high sp3 carbon and hydrogen content were prepared at a current 

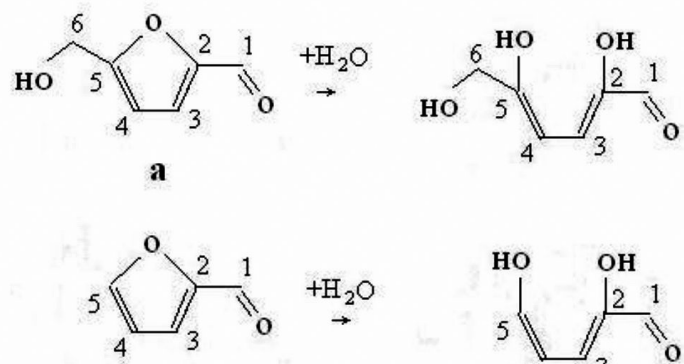

b

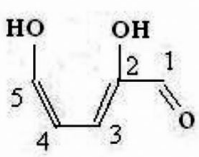

Fig. 8. Mechanism for ring hydrolysis of HMF (a) and furfural (b).

density of $0.001 \mathrm{~mA} / \mathrm{cm}^{2}$. The flexible DLC films can find wide applications in infrared optics, mechanics, electronics and biomedicine.

\section{Acknowledgements}

This work was financially supported by the National Natural Science Foundation of China (No. 50602051)

\section{References}

[1] ItTisanronnachai S., ORIKASA H., InOKUMA N., UozU Y., Kyotani T., Carbon, 46 (2008), 1361.

[2] Ossi P.M., Miotello A., J. Non-Cryst. Solids, 353 (2007), 1860.

[3] Ueda A., Kato D., Sekioka N., Kamata T., KuRita R., Uetsuka H., Carbon, 47 (2009), 1943.

[4] Beghi M.G., CASARi C.S., BAssi A.L., Bottani C.E., Ferrari A.C., Robertson J., Milani P., Thin Solid Films, 420 - 421 (2002), 300.

[5] Jelinek M., Smetana K., Kocoureka T., Mater. Sci. Eng. B-Adv., 169 (2010), 89.

[6] Zahra K., Mahmood G., Elnaz V., Amir S., Mircea V.D., Acta Chim. Slov., 59 (2012), 338.

[7] Tosin M.C., Peterlevitz A.C., Surdutovich G.I., Baranauskas V., Appl. Surf. Sci., 144 - 145 (1999), 260.

[8] Peng X.L., Clyne T.W., Thin Solid Films, 312 (1998), 207.

[9] Nakahigashi T., Tanaka Y., Miyake K., OOHARA H., Tribol. Int., 37 (2004), 907.
[10] TAO Y., YI D.Q., ZHU B.J., WANG D.N., WANG Z.Y., HE K.C., J. Mater. Sci., 46 (2011), 1136.

[11] NIR D., Thin Solid Films, 112 (1984), 41.

[12] Wei Q., Narayan R.J., Sharma A.K., Sankar J., Narayan J., J. Vac. Sci. Technol. A, 17 (1999), 3406.

[13] Tao Y., Chen Z.H., Zhu B.J., HuAng W., Solid State Ionics, 161 (2003), 187.

[14] Paul R., Das S.N., Dalui S., Gayen R.N., Roy R.K., Bhar R., Pal A.K., J. Phys. D Appl. Phys., 41 (2008), 055309.

[15] Dillon R.O., Woolam J.A., Katkanant V., Phys. Rev. B, 29 (1984), 3482.

[16] Gupta S., Patel R.J., J. Raman Spectrosc., 38 (2007), 188.

[17] Thomsen C., Reich S., Phys. Rev. Lett., 85 (2000), 5214.

[18] Heitz T., Drevillon B., Godet C., Bouree J.E., Phys. Rev. B, 58 (1998), 13957.

[19] Robertson J., Mater. Sci. Eng. R, 37 (2002), 129.

[20] Clin M., Durand-Drouhin O., Zeinert A., PICOT J.C., Diam. Relat. Mater., 8 (1999), 527.

[21] Liang C.Y., Marchessault R.H., J. Polymer Sci., 135 (1959), 269.

[22] Titirici M.M., Antonietti M., Baccile N., Green Chem., 10 (2008), 1204.

[23] Titirici M.M., Thomas A., Antonietti M., J. Mater. Chem., 17 (2007), 3412.

[24] Friendmann T.A., Sullivan J.P., KnapP J.A., Tallant D.R., Follstaedt D.M., Medlin D.L., Mirkarimi P.B., Appl. Phys. Lett., 71 (1997), 3820.

[25] Bonelli M., Fioravanti A.P., Miotello A., ORESI P.M., Europhys. Lett., 50 (2000), 501.

[26] Pauleau Y., Residual stresses in DLC films and adhesion to various substrates, in: DONNET C., ERdemir A. (Eds.), Tribology of Diamond-Like Carbon Films, Springer, New York, 2008, p. 102.

[27] Chuntanapum A., Matsumura Y., Indian Eng. Chem. Res., 48 (2009), 9837.

[28] Speight J.G., Lange's Handbook of Chemistry 16th Edition, McGraw-Hill, New York, 2005.

[29] GreEN S., Astrophy. J., 277 (1984), 900.

[30] Tao Y., Yi D.Q., Zhu B.J., Mater. Sci.-Poland, 30 (2012), 17.

Received 2015-05-10

Accepted 2017-10-01 